\title{
Green House Gases (GHG's) Emission Reduction Measures and Verification Challenge at Transport Sector
}

\author{
Haryono Huboyo $^{1 *}$, Hari Wibowo ${ }^{2}$, and Winda Retna Sari $^{3}$ \\ ${ }^{1}$ Department of Environmental Engineering, Diponegoro University J1.Prof.Soedarto, SH Tembalang \\ Semarang Indonesia \\ ${ }^{2}$ Directorate of IGRK and MPV, Ministry of Environment and Forestry, Indonesia \\ ${ }^{3}$ United Nation Development Program (UNDP), Indonesia
}

\begin{abstract}
The Ministry of Transportation Republic of Indonesia adopted several co-benefits activities related to climate change mitigation action through 2010-2014. In order to claim these activities results as climate change mitigation action, Ministry of Environment and Forestry need to verify them. The verification covers data accuracy, consistency, transparency and completeness of data quality and information. The author also verify the other parameters such as the calculation method, managerial system, monitoring system and funding support. In this program, several mitigation actions were implemented such as Area Traffic Control System (ATCS), traffic impact control, parking management, Bus Rapid Transit (BRT) system, smart driving, non-motorized transport, shifting from private vehicles to rail transport, rejuvenating of navigation facilities, aircraft fleet rejuvenation, renewal of the operation and maintenance system of airplane and improvement of flight navigation system during take-off and landing. The absolute difference results between claim and verification for all climate change mitigation actions based on Government Regulation (PP) No. 61/2011 were $13.44 \%$ - 43.5\%. While for mitigation action beyond PP 61/2011, the absolute difference were $0 \%-67.31 \%$. There are no mitigation action satisfying all verification criteria. Based on these verification activities, The Ministry of Transportation should refine the method of mitigation action.
\end{abstract}

\section{Introduction}

National mitigation action to abate GHGs emission facilitated through Presidential Act No. 61/2011[1] will be revised shortly. National target for GHGs emission reduction as stated in the National Action Plan for Reducing GHGs Emission Reduction (RAN-GRK) to attain "Green Indonesia" already has been set. The target is 30\% GHGs emission reduction by 2030 . In order to get effective mitigation action, the implementation of the previous program of mitigation actions should be clarified. Verifications system is a tool to know the effectiveness of the executed programs.

The scope and measurement-reporting-verification (MRV) supervision on mitigation action for GHGs reduction needs support and commitment. This issue is still on negotiation 
stage worldwide [2]. Both developed and non-developed countries have their own views on how to verify their achievement. The developing countries are encouraged to commit on implementing definite mitigation action on GHGs emission reduction by using best available resources in their development [3]. MRV system, which is developed domestically for each country before implementing future recognized global MRV, will raise transparency and build trust inter-countries, funders. This will ultimately ascertain international treaty performance [4]. Verification process will be considered effectively if the process is carried out at proper scale as well as measurement scope based on its initial design [5]. Conformity is the significant part during the verification process. The verification will evaluate several significant mitigation actions which may be highlighted for future development [6]. Ministry of Transportation Republic of Indonesia adopted several co-benefits activities related to climate change mitigation action through 2010-2014

This study will evaluate the achievement of national mitigation actions for reducing GHGs emission from Ministry of Transportation through verification process. Transport sector is the main contributors of anthropogenic GHGs emission in Indonesia. Thus reducing this emission will have positive impact at national scale.

\section{Methodology}

\subsection{Scope of verification}

In verifying each mitigation actions the author did two general steps i.e: a desk review of official report and interview with represented officer of climate change mitigation for each Directorate of Ministry of Transportation. The author reviewed on data accuracy, consistency, transparency also the conformity of the mitigation action to its original planned (PP No.61/2011) as featured in Fig. 1

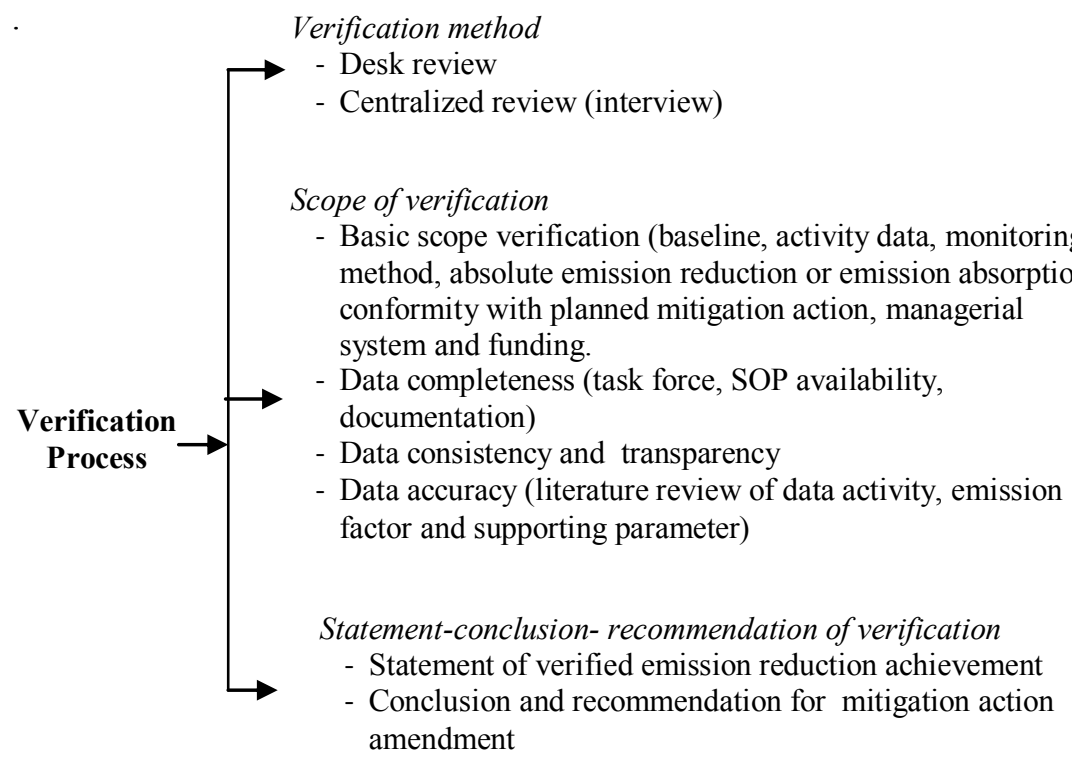

Fig. 1. Scope of verification process. 


\subsection{Reference Method}

The referenced methods used for each Directorate of Ministry of Transportation are as follows:.

Table 1. Methods used for calculating emission reduction

\begin{tabular}{|l|l|}
\hline \multicolumn{1}{|c|}{ Directorate } & \multicolumn{1}{c|}{ Referenced methods } \\
\hline $\begin{array}{l}\text { Directorate General of Land } \\
\text { Transportation (DGLT) }\end{array}$ & $\begin{array}{l}\text { Technical Guidance on Measurement, } \\
\text { Evaluation and Reporting (PEP RAD 2013 } \\
\text { Bappenas) }\end{array}$ \\
\hline $\begin{array}{l}\text { Directorate General of Railway } \\
\text { Transportation } \\
\text { (DGRT) }\end{array}$ & $\begin{array}{l}\text { Calculation method for National Action Plan } \\
\text { for Greenhouse Gas Emission Reduction. } \\
\text { Directorate General of Railway } \\
\text { Transportation }\end{array}$ \\
\hline $\begin{array}{l}\text { Directorate General of Sea } \\
\text { Transportation } \\
\text { (DGST) }\end{array}$ & $\begin{array}{l}\text { USEPA - ICF, 2009 Current Methodologies } \\
\text { in Preparing Mobile Sources-Related Source } \\
\text { Inventories }\end{array}$ \\
\hline $\begin{array}{l}\text { Directorate General of Civil Aviation } \\
\text { Transportation } \\
\text { (DGCAT) }\end{array}$ & $\begin{array}{l}\text { Doc 9988 ICAO: Guidance on the } \\
\text { Development of States' Action Plans on CO2 } \\
\text { Emissions Reduction, 2nd edition 17 March } \\
\text { 2014 }\end{array}$ \\
\hline
\end{tabular}

Note: USEPA: United States Environmental Protection Agency

ICAO: International Civil Aviation Organization

The method used by DGLT is national methodology established by National Agency of Development Planning (Bappenas). While DGRT used their own method which had not been verified externally. Other Directorates adopted international reference method

\section{Results and Discussion}

\subsection{List of Mitigation Actions}

Based on desk review and clarification the author list mitigation actions referred to PP 61/2011 and beyond PP 61/2011. Mitigation actions under PP 61/2011 are as follows: Intelligent Transportation System (ITS) implementation, Traffic Impact Control/TIC, Parking management, Congestion Charging dan Road Pricing, BRT reformation, Public fleet rejuvenation, Gas Fuel Converter Kit, Smart driving or eco-driving, NonMotorized Transport, City railway networking in Bandung, Railway double track development, Electric train procurement, Modification of Diesel train to Diesel-electric train, Mass Rapid Transportation in Jakarta, Airport train to Soekarno Hatta airport, Monorail development in Jakarta, Road preservation.

Mitigation actions beyond PP.61 Tahun 2011 are as follows: Railway double track at North-Java lane, Airplane fleet rejuvenation, Improvement of System and operation maintenance of airplane, Direct routes implementation of Air Navigation (RNAV) 5, Required Navigation Performance (RNP) 10, Navigation of Continous Climb and Descent Operation program i.e Standard Arrival - Standard Instrument Departure (STAR-SIDRNAV1), RNP Approach Procedure (RNP 0.3, RNP 0.1), Rejuvenation of Aids to Marine Navigation.

\subsection{Review on data completeness, consistency, transparency and accuracy}

Reviewing data quality and information of mitigation action achievement was based on three aspects i.e team structure, standard operational procedure and documentation work. 
The author interviewed represented officers in each Directorate who knows or responsible for the mitigation action of emission reduction. While the author did interview the author collected supported data which were kept at their directorate. Periodical restructuring officer as usually occur in state institutions might prevent us to get the right person to be interviewed.

Annual forum in the Centre for Sustainable Transport Management (PPTB) in Ministry of Transportation for constructing mitigation action report is not categorized as evaluation forum of mitigation action due to it is not specific for each Directorate. Generally, there were persons in charge (PIC) of mitigation action to coordinate mitigation action. However these PICs were not supported by a solid team with definite job description therein except in DGCAT. This circumstance was caused by common view that the mitigation action of climate change is not real program (it is just co-benefit of other program). The PICs in DGLT kept the data consistency by using guidance prepared by Bappenas, yet due to data acquisition (particularly activity data) from local officers were not well managed then in the course of calculation, several calculation adjustment which beyond of the referenced method, took place very often.

Monitoring of the program has been already done by the Ministry of Transportation although several parameters were missing such as registered number of urban vehicles since 2013. The biggest challenge is how to maintain continuous monitoring as in the guidance book (PEP Bappenas) numerous data should be collected. If not there should have simplicity of calculation method, without sacrifice the method accountability, to gather complete data from the local officers. The PICs in DGRT had an effort to keep data consistency by using primary data measured at the branch office of state railway enterprise (PT.KAI) as well as secondary data collected by representative institution such as central statistical bureau (BPS). DGRT has specific person to verify the method and implement the method however due to restructuring personnel in DGRT recently, it is difficult to find the supported data of calculation.

PICs of DGCAT maintained data consistency by adopting ICAO standard for their referenced method. Nevertheless, collecting activity data from local airlines was a difficult task. The simple data such as airplane fleet rejuvenation were not used by DGCAT therefore method modification was used instead. This would deny the achievement claim as they adopted different method beyond what they stated originally.

PICs of DGST already kept the data consistency both on conformity of method as well as data collection method. DGST only propose GHGs emission reduction from rejuvenation of Aids to Sea Navigation thus the activity data were well collected from Navigation District offices. Overall, the related report and data sources for implementing the mitigation actions were not officially managed therefore several data calculation seems to use assumption for their calculation or using target achievement as the data sources. The use of data assumption in the calculation was driven by:

a. There is no study yet for the parameters which being used.

b. There is no effective transferred information of activity data from local officers to Ministry of Transportation.

Information on funding sources of each mitigation action is important part for verification. Amount of fund for several mitigation actions were not detected. The report of budget accountability performance of state institution (LAKIP) was the main source of the funding source for each mitigation action. Moreover, several mitigation actions had co-external funding sources such as from private company which may not recorded in LAKIP. 


\subsection{Verification of absolute emission reduction}

Based on desk review and clarification the author verified mitigation actions referred to PP 61/2011 and beyond PP 61/2011 as listed in Table 5. Two big challenges in their achievement to be claimed as verified mitigation actions. First is lack of recorded activity data from the level which the mitigation actions take place. Usually local officers have such above task. Secondly is the verified methodology they used in their calculation. As long as the methodology the used are based on traceable and reliable literatures, then it will have verified methodology.

Table 2. Evaluation of mitigation action documentation

\begin{tabular}{|c|c|c|c|c|c|c|c|c|c|c|}
\hline \multirow{2}{*}{ MITIGATION ACTION } & \multicolumn{2}{|c|}{2010} & \multicolumn{2}{|c|}{2011} & \multicolumn{2}{|c|}{2012} & \multicolumn{2}{|c|}{2013} & \multicolumn{2}{|c|}{2014} \\
\hline & $\mathbf{C}$ & $\mathbf{v}$ & C & $\mathbf{v}$ & $\mathbf{C}$ & $\mathbf{V}$ & C & $\mathbf{v}$ & $\mathbf{C}$ & $\mathbf{v}$ \\
\hline \multicolumn{11}{|l|}{ Land Transportation } \\
\hline ITS implementation & 0.0006 & 0.0014 & 0.0046 & 0.0035 & 0.0453 & 0.0343 & 0.0954 & 0.0724 & 0.117 & 0.0932 \\
\hline Traffic Impact Control/TIC & & & & & & & 0.00007 & 0.0024 & 0.00008 & n.a \\
\hline Bus Rapid Transit (BRT) reformation & 0.0208 & 0.0102 & 0.0226 & 0.0111 & 0.0226 & 0.0111 & 0.0239 & 0.0117 & 0.0529 & 0.0261 \\
\hline Smart driving or eco-driving & $3.7 \mathrm{E}-04$ & $6.2 \mathrm{E}-05$ & $3.8 \mathrm{E}-04$ & n.a & 0.0005 & $8.7 \mathrm{E}-05$ & 0.0006 & $9.8 \mathrm{E}-05$ & 0.0008 & $1.2 \mathrm{E}-04$ \\
\hline Non-Motorized Transport & - & & & & - & & 0.0015 & n.ap & 0.0017 & n.ap \\
\hline \multicolumn{11}{|l|}{ Railway Transportation } \\
\hline Electric train procurement & & & & & 0.0148 & 0.078 & 0.0144 & 0.076 & 0.0085 & 0.045 \\
\hline $\begin{array}{l}\text { TOTAL EMISSION REDUCTION (PP } \\
61 / 2011)\end{array}$ & 0.02177 & 0.01166 & 0.02757 & 0.0146 & 0.0832 & 0.12348 & 0.13587 & 0.16259 & 0.18098 & 0.16442 \\
\hline \multicolumn{11}{|l|}{ Railway Transportation } \\
\hline Railway double track at North-Java lane & & & & & & & & & 0.0043 & 0.01 \\
\hline \multicolumn{11}{|l|}{ Aviation Transportation } \\
\hline Airplane fleet rejuvenation & 0.51144 & n.a & 0.58272 & n.a & 0.16606 & n.a & 0.20714 & n.a & 0.25148 & n.a \\
\hline $\begin{array}{l}\text { Improvement of System and operation } \\
\text { maintenance of airplane. }\end{array}$ & - & & 0.0549 & n.a & 0.0605 & n.a & 0.0462 & n.a & 0.0554 & n.a \\
\hline \multirow{2}{*}{$\begin{array}{l}\text { Direct routes implementation, RNAV5, } \\
\text { RNP10 }\end{array}$} & - & & 0.11958 & n.a & 0.13393 & & 0.15 & & & \\
\hline & - & & 0.05979 & n.a & 0.06697 & & 0.075 & & & \\
\hline $\begin{array}{l}\text { Navigation of Continous Climb and } \\
\text { Descent Operation (STAR-SID-RNAV1) }\end{array}$ & - & & 0.47833 & & 0.53573 & & 0.60002 & & & \\
\hline $\begin{array}{l}\text { RNP Approach Procedure (RNP 0.3, RNP } \\
0.1 \text { ) }\end{array}$ & - & & 0.0287 & & 0.03214 & & 0.036 & & & \\
\hline Rejuvenation of Aids to Marine Navigation & - & & & & & - & & & 0.1179 & 0.0076 \\
\hline $\begin{array}{l}\text { TOTAL EMISSION REDUCTION (Non } \\
\text { PP 61/2011) }\end{array}$ & 0.51144 & & 1.32402 & & 0.99533 & & 1.11436 & & 0.42908 & 0.0176 \\
\hline TOTAL EMISSION REDUCTION & 0.5332 & 0.0117 & 1.3516 & 0.0146 & 1.0785 & 0.12349 & 1.2502 & 0.1626 & 0.61006 & 0.18202 \\
\hline
\end{tabular}

Notes:

Reliable method, complete activity data-supported parameters Reliable method, incomplete activity data-supported parameters Unreliable method, complete activity data-supported parameters Unreliable method, incomplete activity data-supported parameters n.a : not available, n.ap: not applicable C: Claimed, V: Verified 
Among all mitigation actions, only mitigation action from DGST which calculate $\mathrm{CO}_{2}$ equivalent as recommended by Ministry of Environment and Forestry. Other directorates only calculated $\mathrm{CO}_{2}$ reduction.

\section{Conclusion and Recommendation}

There are no mitigation action satisfying all verification criteria. Partial fulfillment of verification criteria was achieved for several mitigation actions as they lack of calculation reference. On average the absolute difference between claim to verified data in $2010-2014$ is about $88 \%$. Based on these verification activities, The Ministry of Transportation should refine the method of mitigation action.

Untuk promote verifiable mitigation action, the Ministry of Transportation should conduct Quality Assurance (QA) and Quality Control (QC) on their mitigation actions. Documented SOP should be imposed to prevent uncontrolled scope of mitigation action. This SOP should be robust and flexible to anticipate the dynamics of mitigation action implementation in the field.

The completeness of supporting data such as baseline emission, managerial system, funding support documentation should be disclosed comprehensively so as to get reliable mitigation actions. To have an efficient mitigation action, the Ministry of Transportation should prioritize mitigation actions which may have huge amount of emission reduction for their measurement and monitoring program. This is get optimum amount of claimed emission reductions

\section{References}

1. Presidential Act. National Action Plan for GHGs Emission Reduction. (2011).

2. J.Morlot, J. Ellis J; S.Moarif. Measurable, Reportable and Verifiable Mitigation Actions and Support, A summary of OECD/IEA analyses for COP 15. Available at www.oecd.org/env/cc/mrv (2015)

3. Gu, F. Teng, Y. Wang. Sector Mitigation Policies and Methods in China: Measurable, Reportable, and Veriable Mechanisms. Adv. in Climate Change Research 2: 115-123 (2011)

4. P. Hogan, A. Falconer, V. Micale, A.Vasa, Y. Yu, X. Zhao. Tracking Emissions and Mitigation Actions: Current Practice in China, Germany, Italy,and the United States. Report of Climate Policy Initiative (2012)

5. L. Larmuseau. MRV: -NAMA's -Future and challenges. 11th Annual IEA-IETA-EPRI Workshop on Greenhouse Gas Emission Trading. Paris October (2011).

6. N Singh, J Finnegan, K Levin. MRV 101: Understanding Measurement, Reporting, and Verification of Climate Change Mitigation.

https://www.wri.org/sites/default/files/MRV 101 0.pdf. Accessed by December 2017.( 2017). 